\title{
Characterization of an Intraplate Seismogenic Zone Using Geophysical and Borehole Data: The Vila Franca de Xira Fault, Portugal
}

João Carvalho ${ }^{1,2, *}$, Daniela Alves ${ }^{1,3}$, João Cabral ${ }^{4}$, Ranajit Ghose ${ }^{5}$, José Borges ${ }^{6}$, Ruben Dias ${ }^{1}$, Elsa Ramalho ${ }^{1}$, Bento Caldeira ${ }^{6}$, João Casacão ${ }^{6}$, and Jaime Leote ${ }^{1}$

\begin{abstract}
The Vila Franca de Xira (VFX) fault is a regional fault zone located about $25 \mathrm{~km}$ northeast of Lisbon, affecting Neogene sediments. Recent shear-wave seismic studies show that this complex fault zone is buried beneath Holocene sediments and is deforming the alluvial cover, in agreement with a previous work that proposes the fault as the source of the 1531 Lower Tagus Valley earthquake. In this work, we corroborate these results using $S$-wave, $P$-wave, geoelectric, ground-penetrating radar and borehole data, confirming that the sediments deformed by several fault branches are of Upper Pleistocene to Holocene. Accumulated fault vertical offsets of about $3 \mathrm{~m}$ are estimated from the integrated interpretation of geophysical and borehole data, including 2D elastic seismic modeling, with an estimated resolution of about $0.5 \mathrm{~m}$. The deformations affecting the Tagus alluvial sediments probably resulted from surface or near-surface rupture of the VFX fault during $M \sim 7$ earthquakes, reinforcing the fault as the seismogenic source of regional historical events, as in 1531, and highlighting the need for preparedness for the next event.
\end{abstract}

Cite this article as Carvalho, J.,

D. Alves, J. Cabral, R. Ghose, J. Borges,

R. Dias, E. Ramalho, B. Caldeira,

J. Casacão, and J. Leote (2020).

Characterization of an Intraplate

Seismogenic Zone Using Geophysical and Borehole Data: The Vila Franca de Xira Fault, Portugal, Seismol. Res. Lett. XX, 1-11, doi: 10.1785/0220190317.

Supplemental Material

\section{Introduction}

The metropolitan area of Lisbon and the Lower Tagus Valley (LTV) region are roughly located $400 \mathrm{~km}$ north of the AfricaIberia plate boundary zone (Fig. 1). In spite of a moderate seismicity (Fig. 1), the region experiences occasionally destructive earthquakes, generated at the plate boundary or at local intraplate faults. Though low slip rates have been estimated for these local, regional faults, they can generate relatively frequent moderate to large (M 6.5+) earthquakes, causing major damage and loss of lives (e.g., Justo and Salwa, 1998; Cabral et al., 2003; Teves-Costa et al., 2019). This short recurrence time may be due to the existence of multiple active faults and time clustering induced by stress changes caused by fault interaction and/or by variable rates of Coulomb stress accumulation.

One of these regional faults extends to the northeast of Lisbon, crossing the Vila Franca de Xira (VFX) city (Fig. 2) only $25 \mathrm{~km}$ from the densely populated Portuguese capital. This tectonic structure was generated in the Mesozoic as a large normal-fault zone and was reactivated as an oblique left-lateral reverse fault in the Cenozoic. Continued slip on the fault zone certainly postdates tilted and faulted Miocene (Tortonian) sediments that are overthrust by Jurassic rocks south of
VFX, as also suggested by legacy hydrocarbon exploration seismic data (Cabral et al., 2003; Carvalho et al., 2006). These data show that the VFX fault is part of a fault system in the upper crust (e.g., Rasmussen et al., 1998) and that it extends northeast and southwest of its known outcrops, hidden beneath the alluvial cover of the Tagus River (Fig. 2).

Based on seismic intensity distribution data, the VFX fault is thought to have generated several destructive earthquakes that damaged the city of Lisbon and neighboring localities, as in 1344 (e.g., Cabral et al., 2003; Ferrão et al., 2016) and 1531 (Justo and Salwa, 1998; Baptista et al., 2014; Ferrão et al., 2016). The 1531 (modified Mercalli intensity VIII-IX) Lisbon earthquake caused more than 1000 fatalities (Justo and Salwa, 1998; Baptista et al., 2014). However, no direct evidence of post-Miocene fault

\footnotetext{
1. Estrada da Portela-Zambujal, Alfragide, Amadora, Portugal; 2. Now at Galp Exploração e Produção, Lisbon, Portugal; 3. Now at Randstad, Lisbon, Portugal; 4. Instituto Dom Luiz, Universidade de Lisboa, Lisbon, Portugal; 5. Department of Geoscience and Engineering, Delft University of Technology, GA Delft, The Netherlands; 6. Departamento de Física da Universidade de Évora, Instituto de Ciências da Terra- polo Évora, Colégio Luís António Verney, Évora, Portugal *Corresponding author: joao.carvalho@Ineg.pt (c) Seismological Society of America
} 
(a)

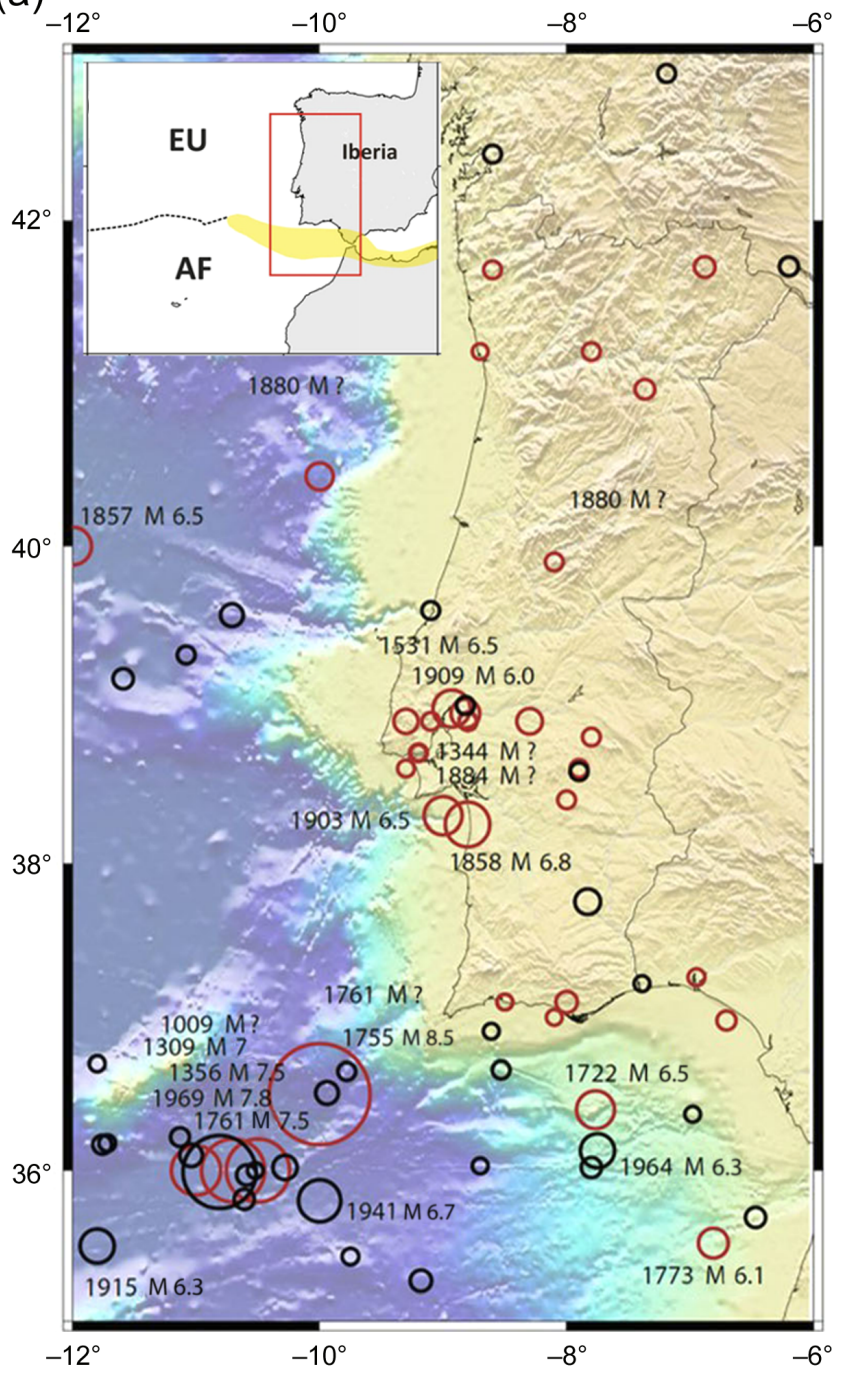

activity has been found yet. For nearly $20 \mathrm{~km}$, this fault outcrops as a steep fault with an east-verging reverse movement component. Interpretation of shear-wave reflection data obtained in the last $10 \mathrm{yr}$ strongly suggests that the Holocene sediments are deformed by several hidden fault branches in the alluvial plain east of the previously referred fault outcrop, where the fault is hidden under a cover of recent alluvium of the Tagus River. Therefore, corroboration of the VFX fault activity and estimation of the fault rupture parameters in Holocene sediments are extremely important for seismic hazard and risk evaluation, and are the goal of the current study.

Opening a trench across a fault and dating the young sediments affected by prior surface ruptures is the most adequate approach for investigating the history of seismogenic faults, but this is often difficult to accomplish in areas of high sedimentation rates or in urbanized or cultivated areas (as in the study area). Furthermore, when the fault is buried beneath sediments and the scarps generated by the coseismic surface faulting are erased by the surface processes and anthropogenic activity during the long return period of rupture events (such (b)

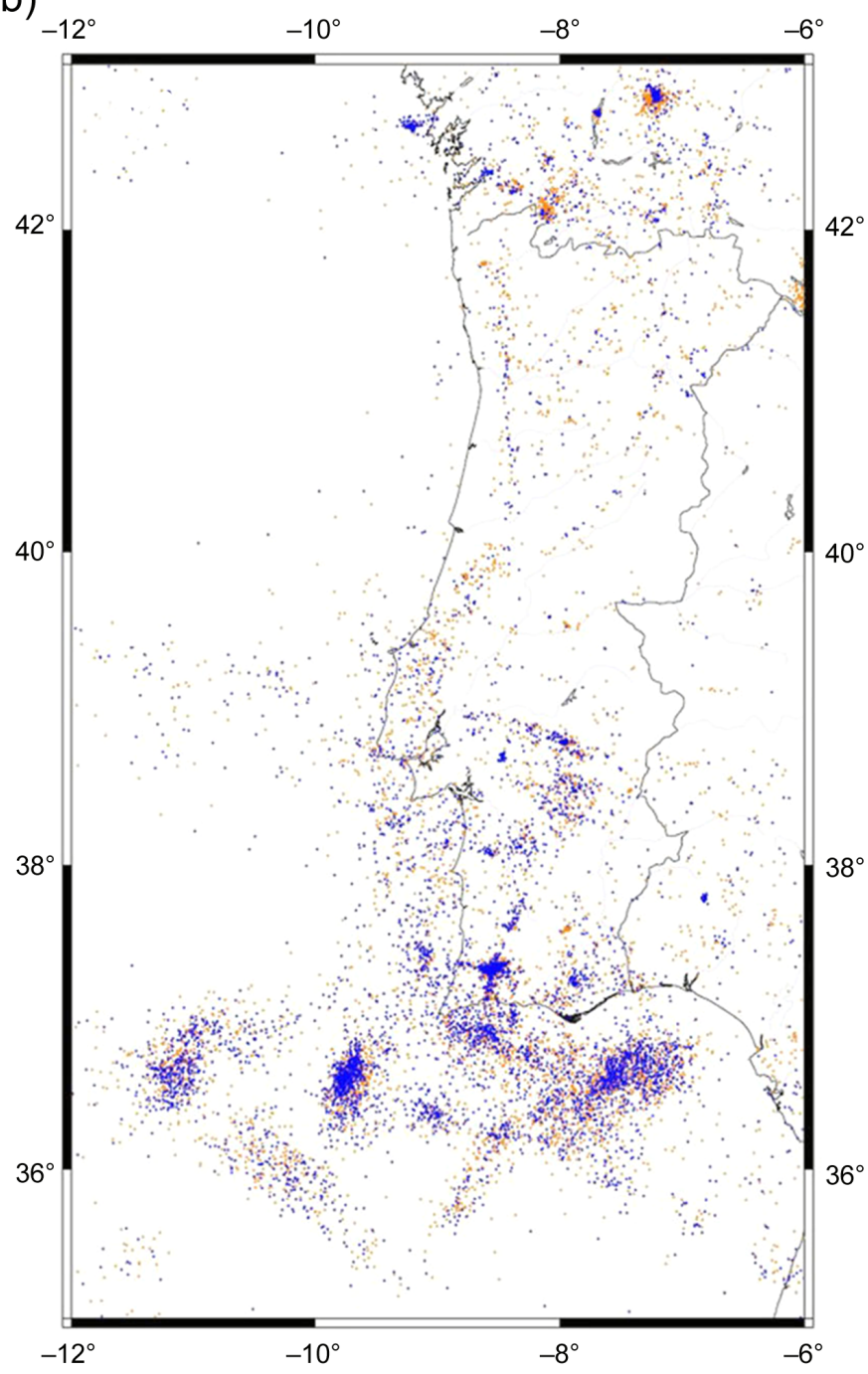

Figure 1. Seismotectonic setting of mainland Portugal and adjacent area (adapted from Custódio et al., 2019). (Inset) Schematic tectonic setting showing location (rectangle) relative to the Eurasian (EU) and African (AF) tectonic plates. Yellow indicates diffusive deformation zone. (a) Historical (up to 1910) and instrumental earthquakes with $\mathbf{M} \geq 5$ displayed as circles, in which radius correlates to earthquake magnitude. For $\mathbf{M} \geq 6$ earthquakes, the dates and respective magnitudes are displayed. "M?," unknown magnitudes. (b) Instrumental seismicity from 1995 to 2013 (source: Portuguese Institute for the Sea and Atmosphere [IPMA]); rectangle shows location of the study area. The color version of this figure is available only in the electronic edition.

as the study area), the location of boreholes and trenches must be guided by prior geophysical studies.

Seismic reflection is one of the most adequate methods for investigating shallow fault zones (e.g., Woolery et al., 1993; Benson and Mustoe, 1995; Floyd et al., 2001; Wang et al., 2004; Campbell et al., 2010). In soft sediments, $S$ waves often provide a higher resolution than $P$ waves and a greater 


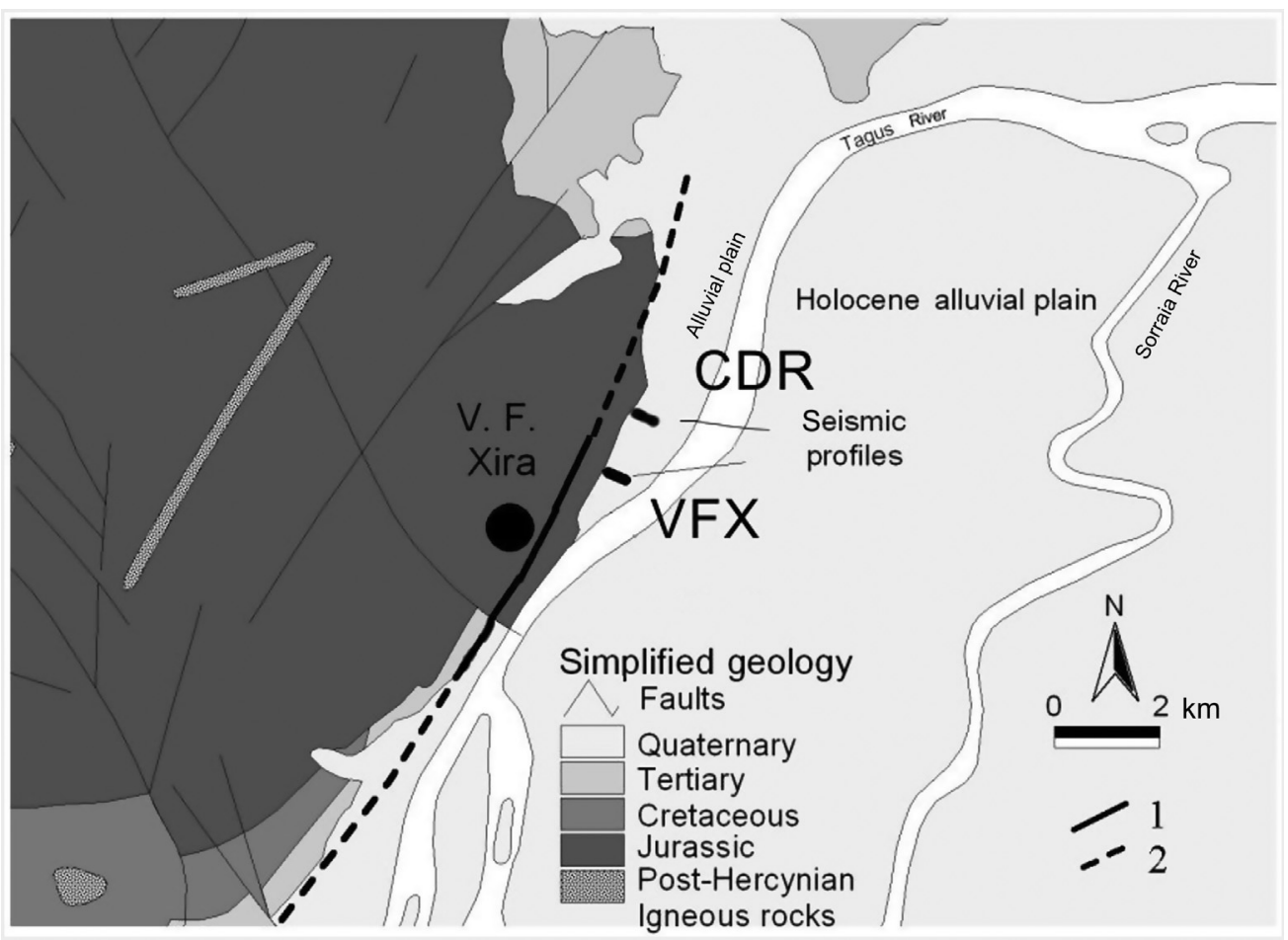

Figure 2. Location of the Vila Franca de Xira (VFX) fault and geophysical data acquisition sites of VFX and Castanheira do Ribatejo (CDR) over a simplified geological map (Laboratório Nacional de Energia e Geologia [LNEG], 2010). 1, outcropping VFX fault; 2, inferred prolonging of the VFX fault. geophysical data obtained at these two sites, $P$-wave seismic, ERT, and GPR, and using unpublished cone penetration test (CPT) and borehole data, we show that the observed deformation affects alluvial sediments younger than $20 \mathrm{ky}$ old and that this deformation is part of a deep-rooted fault system with the VFX fault orientation.

Guided by the geophysical interpretation, three trenches were opened in 2013 at the CDR site. Unfortunately, the trenches supplied inconclusive results. Therefore, to estimate several seismogenic parameters, we performed $2 \mathrm{D}$ elastic modeling, which suggests a $3 \mathrm{~m}$ vertical offset of intra-alluvial horizons aged approximately $10 \mathrm{ky}$. The trench results together with the ERT and GPR results are presented as supplemental material to this article.

sensitivity to the subtle changes in the sediment composition (e.g., Ghose and Goudswaard, 2004; Ghose, 2012).

Methods such as ground-penetrating radar (GPR) or electrical resistivity tomography (ERT) are also adequate for studying shallow faults. However, GPR and ERT have depth penetration problems in clayish environments with a shallow water table and high electrical conductivity, such as the study area. Even using proper acquisition parameters, local soil conditions prevent electrical current from penetrating and most of the energy is reflected at the water table, located in some places at $1 \mathrm{~m}$ depth. Nevertheless, if a proper antenna and current intensity is chosen and care is taken in data processing, useful results may be achieved in some areas.

Under the scope of several scientific research projects, multiple geophysical surveys were carried out at two places located northeast of Lisbon to locate the VFX fault beneath the Holocene cover: VFX and Castanheira do Ribatejo (CDR). The two sites, approximately $2 \mathrm{~km}$ apart, are located in the alluvial plane, about $500 \mathrm{~m}$ east of the known fault trace (Fig. 2).

Using the integration of multiple evidences of faultingrelated deformation in soft sediments based on shear-wave data proposed by Ghose et al. (2013), Carvalho et al. (2016) have shown that soft-sediment deformation affects shallow sediments in the two above-mentioned sites, strongly suggesting that the fault is active. In this work, we present further

\section{Previous Work and Borehole Data}

Multiple boreholes drilled earlier in the study area for engineering and hydrogeological purposes show that, at the VFX and CDR sites (Figs. 3a,b and 4a,b, respectively), the upper sediments in the Tagus River alluvial plain are composed of a clayish and silty unit locally alternating with sand lenses of various thicknesses. The alluvial basement differs from the west side of the VFX seismic profiles, where the alluvial sediments rest on Jurassic rocks at a depth of about $20 \mathrm{~m}$, relatively to the east side of the seismic profiles where, according to borehole data, the base of the alluvium is located at around $52 \mathrm{~m}$ depth overlying Neogene sediments and the Jurassic basement is reached below $200 \mathrm{~m}$ depth.

In spite of this large depth difference for the Jurassic rocks within such a short distance (about $300 \mathrm{~m}$ ) and nearby outcrop data that strongly suggest the presence of a large fault affecting Mesozoic rocks that prolongs beneath the alluvial sediments, the sparse drilling data and the typical alluvial depositional patterns prevented the confirmation of faulting in the Holocene alluvium.

With the goal of locating the VFX fault beneath the Holocene to Upper Pleistocene alluvial cover and determining whether the recent sedimentary cover is affected by the fault activity, $P$-wave seismic reflection and vertical electrical soundings were previously acquired and interpreted at the VFX site 
(a)

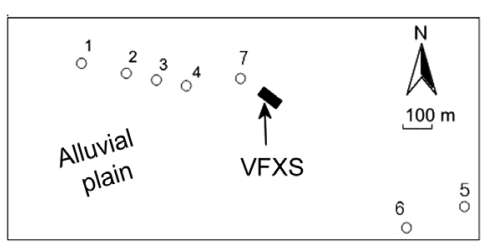

(b)
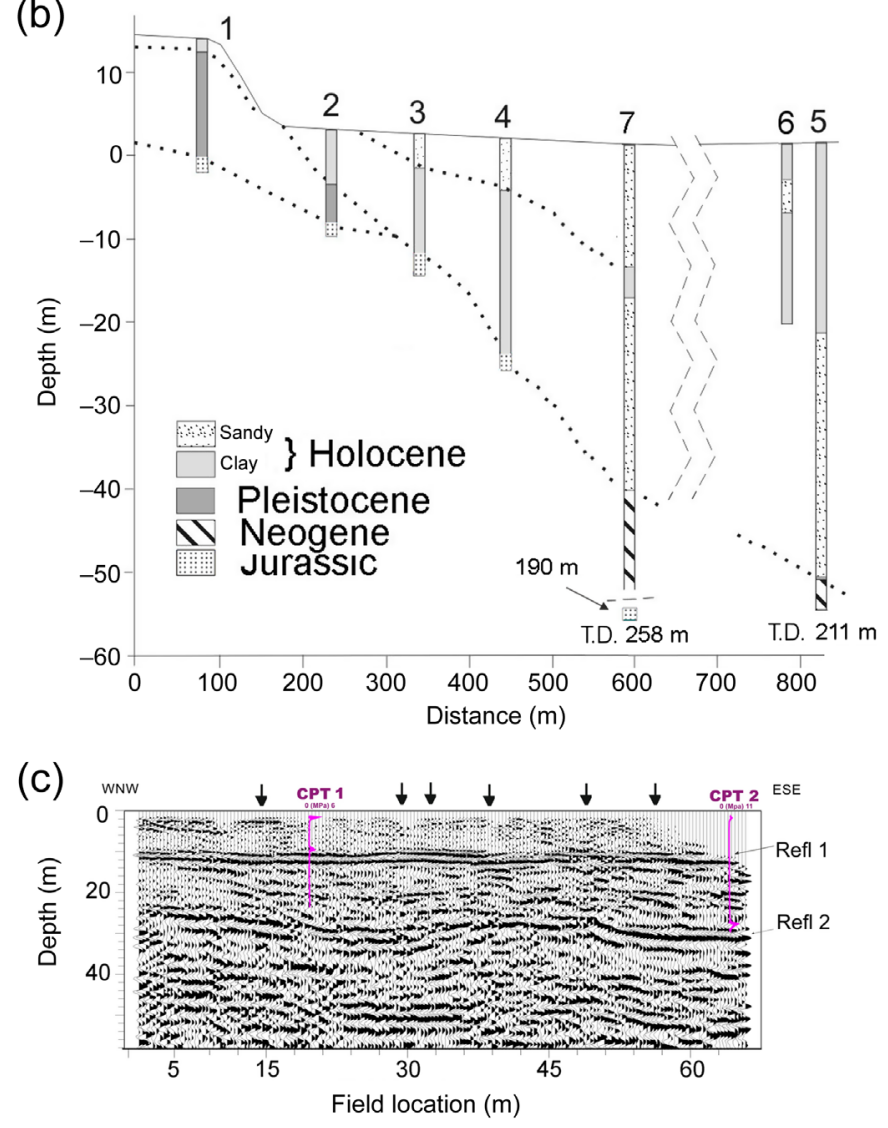

Figure 3. (a) Map view of borehole data in the vicinity of the VFX site, drilled over alluvium; VFXS, S-wave reflection profile. (b) Cross section of boreholes (projected) shown in (a); dotted lines indicate lateral correlation of major stratigraphic units. (c) Migrated, depthconverted S-wave stacked section at VFX site (adapted from Carvalho et al., 2016), with cone penetration test (CPT) data overlaid; interpreted fault branches are marked by arrows. ESE, east-southeast; T.D., total depth; WNW, west-northwest. The color version of this figure is available only in the electronic edition.

(fig. 2 of Carvalho et al., 2006). Several fault segments were interpreted in this dataset at depths below $40 \mathrm{~m}$, confirming the presence of the VFX fault zone beneath the alluvial cover (which in the area is about $50 \mathrm{~m}$ thick), but the limited resolution in the $P$-wave reflection data (about $2-3 \mathrm{~m}$ ) made it very difficult to identify any fault branch in the overlaying sediments. This led to the acquisition in 2009 at the same location of an $S$-wave seismic reflection dataset. The original processed stacked sections for VFX and CDR can be found in Carvalho et al. (2016), which showed for the first time that several fault segments very probably affect the alluvial sediments at shallow depths $(8-10 \mathrm{~m})$.

\section{New Borehole Data and Correlation with S-Wave Seismic Data}

Our major goal was to identify the depth to the base of the Upper Pleistocene to Holocene alluvial cover in the seismic data to prove that deformation detected in these data is recent. Identification of other faulted and deformed seismic interfaces would be very important as it could provide information on the history of fault activity and allow for the estimation of slip rates.

Laboratório Nacional de Energia e Geologia (LNEG) is the Portuguese repository for borehole data, and several boreholes were used by Carvalho et al. $(2006,2016)$ to interpret the geophysical data at the VFX site. However, a borehole located closer to the VFX site was identified under the scope of this work; it was not part of LNEG database at the time. This borehole, reaching a depth of more than $200 \mathrm{~m}$, is located about $100 \mathrm{~m}$ northwest of the western end of the VFX profiles (borehole 7 in Fig. 3a,b). Furthermore, in 2009, two CPTs were conducted at two locations over the $P$-wave seismic profile (unpublished data). In 2009, $S$-wave data were acquired to sample one of the shallow fault segments detected in the $P$-wave survey and to cover the location of the two CPTs. The $S$-wave seismic section with location of the CPT overlaid is shown in Figure $3 \mathrm{c}$. The seismic section was depth-converted using a $1 \mathrm{D}$ velocity function built from average stacking velocities.

At the CDR site, previously analyzed boreholes (Carvalho et al., 2016) were located about $200 \mathrm{~m}$ from both sides of the shear-wave seismic profiles (Fig. 4a). For this work, additional borehole data closer to the seismic profiles were used. These boreholes were drilled for water supply (JK-1, PS-1, JK-2, and $\mathrm{JK}-3$ ) and include unpublished geophysical logs, namely single-point resistance (SPR), spontaneous potential (SP), and natural gamma-ray (GR) logs, which are shown in Figure $4 \mathrm{~b}$.

Next, we use the general stratigraphy of the Upper Pleistocene-Holocene deposits in the LTV and sediment dating in the region (Ramos et al., 2002; Vis and Kasse, 2009; Vis et al., 2016) to analyze borehole data at both sites, and we correlate the lithological interfaces intersected by boreholes with the seismic data to study the fault activity through time.

Figure 4 displays lithological, SP, SPR, and GR logs of borehole PS-1, which was located only a few meters from the $S$-wave profile. The correlation of the borehole logs with the (closest) section of the stacked $S$-wave profile shows a clear correspondence between the reflective events and major property changes and lithological boundaries in the geophysical logs.

Looking at the borehole data in Figures 3 and 4, it is not straightforward to correlate the logs with the general stratigraphic approach of Vis and Kasse (2009, see their fig. 6 and table 1) for the fluvial system of the LTV. According to Vis and Kasse (2009), the lithologies and facies within the VFX area are dominated by clays, silty clays, loams, and fine 
(a)
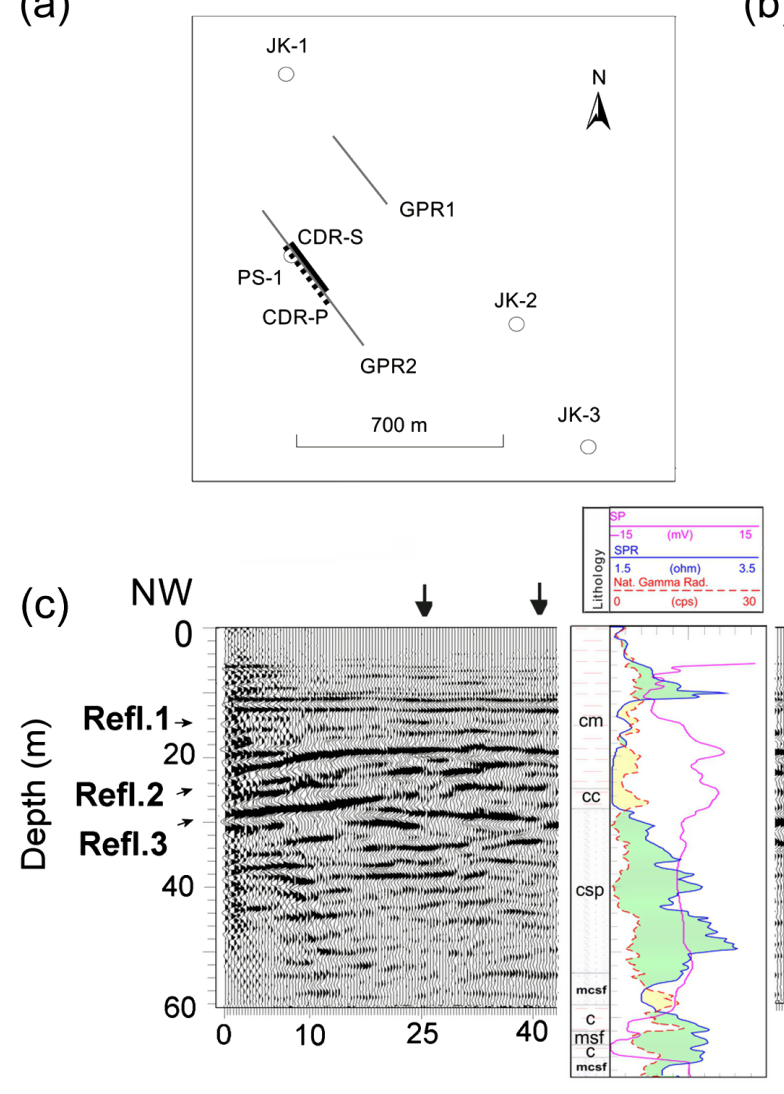

to coarse sands. Stratigraphic units FU-5A and 5B (at the top) have a predominance of fine to coarse sands and unit FU-1 (base of alluvial sediments) of sands with gravel at the base. The uppermost unit at the valley axis in the VFX area corresponds to unit FU-3A (Vis and Kasse, 2009) (structureless clay and silty clay). The other units have a predominance of clays, silty clays, and loam and may include sand bodies from a few centimetres thick to several meters. The vertical transitions from unit to unit can either be gradual, sharp, or erosive.

Looking at these vertical lithological changes, one should expect few strong seismic reflectors, as observed in the stacked sections at VFX and CDR. The best seismic markers should be: M1, which is interpreted as the contact between mediumcoarse sands of unit FU-5A of Vis and Kasse (2009), at the top, with sandy clay loam with sand spots of the FU-4 unit, probably at about $10 \mathrm{~m}$ depth; M2, which is interpreted as equivalent to the erosive contact located at a depth of around $26 \mathrm{~m}$ below mean sea level (m.s.l.) in the VFX core of Vis and Kasse (2009), of the FU-4 unit with the underlying FU-3A unit, which is composed of clay and silty clay with fine sands lamination, presenting lag deposits with clay pebbles; this erosive contact may represent a strong reflector if there are sand lenses at the base of FU-4 unit; and M3, which is interpreted as the sharp to gradual transition at the base of the clay and silty clay loam unit FU-2 to the underlying sands and gravels of unit FU$1 \mathrm{~B}$, placed at about $47 \mathrm{~m}$ below m.s.l. in the VFX core of Vis and Kasse (2009).
Figure 4. (a) Map view of borehole data in the vicinity of the CDR site, drilled over alluvium. CDR-P, $P$-wave profile; CDR-S, shearwave profiles; ground-penetrating radar (GPR) (i.e., GPR1 and GPR2), GPR profiles; JK, PS-1, boreholes. (b) Cross section of boreholes (projected) and respective geophysical logs shown in (a); Gamma, gamma-ray log; SPR, single-point resistance log; dotted lines indicate lateral correlation of major stratigraphic units (M1-3, see in the New Borehole Data and Correlation with S-Wave Seismic Data section). Ba, probable base of alluvium. (c) Reprocessed, migrated, depth-converted S-wave stacked section at CDR site with nearby borehole (PS-1) and logging data, plotted at correspondent location; SP, spontaneous potential log; lithologic log: C, clay; CC, compact clay; $\mathrm{cm}$, clays and silty clays; csp, coarse sand with pebbles; mcs, medium to coarse sand with feldspar grains; msf, medium sand with feldspar grains; interpreted fault branch locations are marked by arrows. NW, northwest; SE, southeast. The color version of this figure is available only in the electronic edition.

At the VFX site, we can observe in Figure $3 c$ that the obtained cone tip resistance $\left(q_{c}\right)$ correlates well with seismic reflective horizons. The CPT data were digitized considering only the largest changes observed to improve visibility of the CPT data overlaid to the seismic section. We interpret the $10 \mathrm{~m}$ reflector visible in the $S$-wave seismic section shown in Figure $3 \mathrm{c}$ as an intra-alluvial lithological transition. There is a slight vertical mismatch of this interface located at about $10 \mathrm{~m}$ depth with the CPT data because we are using $1 \mathrm{D}$ average stacking velocities to depth-convert the temporal seismic data, as the use of the CPT 
velocities introduced false structures in the stacked section, possibly due to lateral velocity variations in the study area. The $10 \mathrm{~m}$ interface was almost not detected at CPT2 (a small peak in the original nondigitized data is however observed) due to the lateral lithological changes present in the area.

This $10 \mathrm{~m}$ depth interface possibly corresponds to marker M1 (transition of stratigraphic units FU-5 to FU-4 of Vis and Kasse, 2009). A sample collected at that depth in the VFX core of Vis and Kasse (2009), located about $5 \mathrm{~km}$ eastward, was dated 4090-3850 yr B.P. Also, the deeper reflector displayed in the stacked section of Figure $3 \mathrm{c}$ corresponds to an average depth of about $28 \mathrm{~m}$ varying from a depth of $26 \mathrm{~m}$ at the western end to $32 \mathrm{~m}$ at the eastern end of the profile. CPT1 did not reach this depth, but a clear increase in $q_{c}$ is observed at around $26 \mathrm{~m}$ in CPT2. Standard penetration test data of borehole 7, the closest to the profile (Fig. 3), shows a compaction increase at $27 \mathrm{~m}$ depth (not shown here). This depth matches approximately the transition of stratigraphic unit FU-4, consisting of sandy clay loam with sand spots, to unit FU-3A, made of clays and silty clays with fine sand lamination, in the VFX core of Vis and Kasse (2009) (this transition corresponds to M2). Looking at the boreholes presented in Figure $3 \mathrm{~b}$ and other available nearby wells (not shown here), sand lenses within clays and silty clays predominate in the area, suggesting that the seismic data at the VFX site might be indeed showing M2, as at the base of FU-4 there is an increase of grain size (Vis and Kasse, 2009). A sample collected at this depth in a VFX borehole of Vis and Kasse (2009) was dated as $10,200-9,780$ yr B.P.

The base of the alluvium (base of unit FU-1B) was found at depths of 44 and $54 \mathrm{~m}$ in boreholes 7 and 5, respectively, shown in Figure $3 \mathrm{a}$ and $3 \mathrm{~b}$. This geological interface was not reached in the seismic data probably due to the lack of source energy.

At the CDR site, the geophysical and lithological logs show a thick column of clays, loam, and silts with occasional thin, sand laminae, which thickens from west $(24 \mathrm{~m})$ to east $(40 \mathrm{~m})$. The thick clayish sediments possibly correspond to clayish units FU-4, FU-3A, and FU-2 of Vis and Kasse (2009), which in the restricted areas of these boreholes do not present thick sand layers.

The CDR stacked section shows a continuous reflector at a constant depth of about $10 \mathrm{~m}$, similar to that at VFX, which coincides with the shallowest sharp change in the SP and GR logs (Fig. 4b). According to the lithological log of borehole PS1, located astride the seismic profile, this transition occurs inside a layer of clays, silts, and loam and does not correspond to any lithological change. The PS1 logs suggest that this intra-alluvial reflector is possibly a (spatially) localized thin sand layer within the silts and clays, as frequently observed within these Holocene sediments.

The second reflector in the CDR stacked section shows a convex, lens-like form that reaches a minimum depth of $18 \mathrm{~m}$, apparently limiting a sedimentary body that thins to the east as the reflector deepens. Although the borehole PS-1 was drilled using bentonite clay, there is no information in the borehole report about its $\mathrm{Cl}^{-}$content. Therefore, equivalent $\mathrm{NaCl}$ content cannot be estimated and a proper interpretation of the SP log cannot be made (Ramalho et al., 2009). However, deflections on the SP curve may occur due to numerous reasons; in this case, due to the strong normal SP deflection and the lowest SPR values between about 20 and $30 \mathrm{~m}$ depth, we infer the presence of a less permeable layer with the lowest electrical resistivity (Chapellier, 1992), possibly a loam layer with brackish water within the clay column. Although this layer was not identified in the lithological log, it may be the reason for the simultaneous occurrence of the observed geophysical log features and for having been detected by the $S$-wave data.

In the stacked section, reflector 3 is at an average depth of $28 \mathrm{~m}$ and is visible in borehole PS-1 as a rise in the GR and a strong decrease in the SP $\log$ (Fig. 4c). In the boreholes, it marks a change of compact clays to coarse sands with pebbles that thickens from the western end of the seismic profile to the location of borehole PS1, where it reaches its maximum thickness $(24 \mathrm{~m})$, and then thins toward the east. This transition very possibly corresponds to the top of the sand and gravel FU-1B unit of Vis and Kasse (2009) (M3 in Fig. 4b). The core used by these authors is located in the center of the LTV where the alluvial sediments are thicker and the top of FU-1B is at a greater depth $(\sim 47 \mathrm{~m})$. A sample collected at a depth of $33 \mathrm{~m}$ from a well sited about $2 \mathrm{~km}$ north of the CDR seismic profiles was dated 14,120-13,809 cal. B.P. (M. C. Freitas et al., unpublished report, 2018).

The base of the coarse sand with a pebbles layer at about $50 \mathrm{~m}$ depth, observed in Figure 4 boreholes, is very probably the base of the Upper Pleistocene-Holocene alluvial sediments. It was not detected in the seismic profiles. Beneath this horizon, a series of alternating sands with feldspars and clays of Pliocene or Miocene, that constitute the valley basement, was crossed in the boreholes.

\section{New Field Data Acquisition and Processing: High-Resolution P-Wave Reflection \\ $P$-wave seismic data}

After the acquisition of the $S$-wave reflection data at the CDR site, a $P$-wave seismic profile approximately $200 \mathrm{~m}$ long was acquired in this study with an accelerated weight drop source of $250 \mathrm{~kg}$ from which the seismic energy was capable to reach hundreds of meters of investigation depth. This profile was initiated $10 \mathrm{~m}$ east of the previous $S$-wave profile, totally overlapping this 160 -meter-long $S$-wave profile. The goal was to confirm that the shallow fault branches interpreted in the $S$ wave data could be associated with a deeply rooted fault zone and, together with previous $P$-wave data acquired at the VFX site (Carvalho et al., 2006), they could verify if this fault zone was compatible with the VFX fault geometry and kinematics. 
(a)

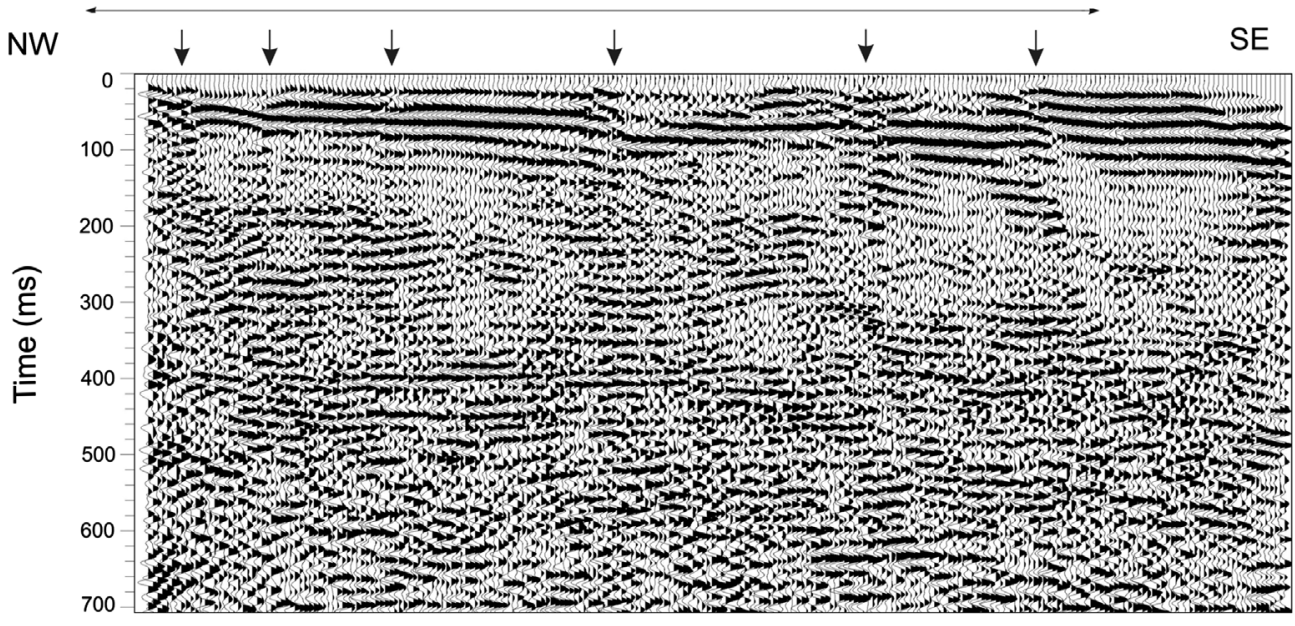

(b)

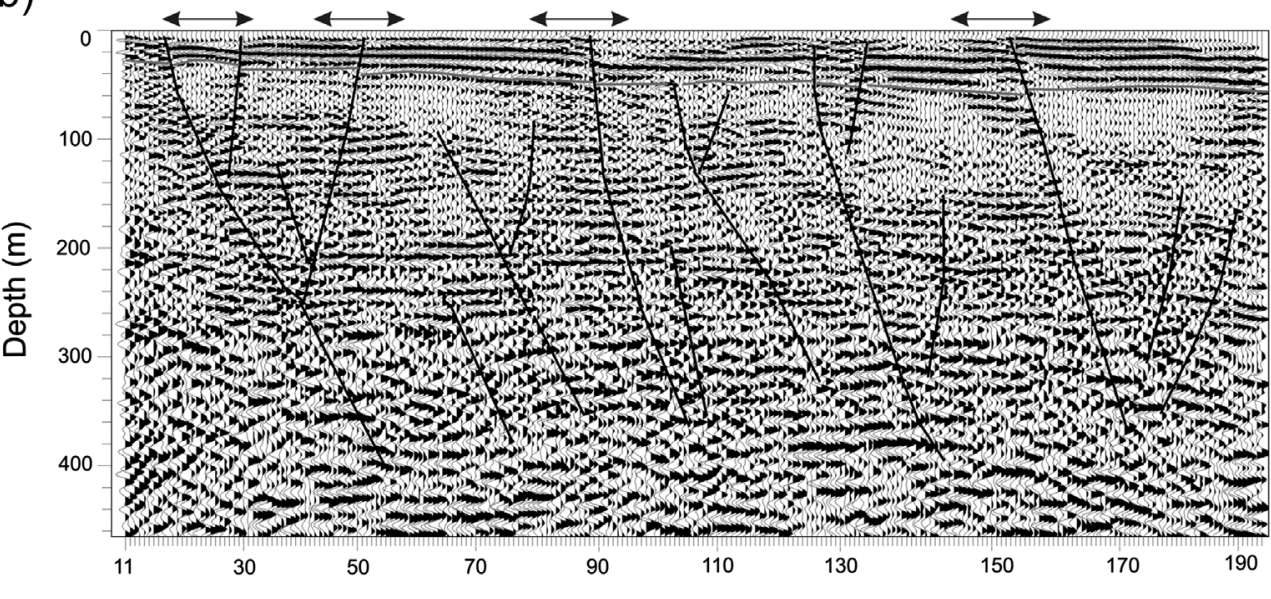

Figure 5. (a) Post-DMO P-wave stacked seismic profile acquired at the CDR site; distance is relative to the start of profile CDR-S (location in Fig. 4a); horizontal, long, double-sided arrows indicates overlap with the S-wave profile CDR-S; interpreted shallow fault branches are marked by vertical arrows. (b) Depth-migrated $P$-wave seismic profile; short horizontal arrows and letters mark location of trenches; black lines, interpreted faults; gray line, base of alluvium.

filtering $(25-120 \mathrm{~Hz})$, two passes of velocity analysis, and CMP stacking. Finally, a split-step depth migration was carried out after frequency-wavenumber dip move out (DMO; Hale, 1984) and post-DMO velocity analysis were applied. The data were stacked and depth-migrated using a $1 \mathrm{D}$ velocity function constructed from horizon velocity analysis and constant velocity stacks. The $P$-wave stacked section for the CDR site is shown in Figure 5. Comparison of this image with the $S$-wave stacked section (Fig. 4) shows the resolution improvement using $S$ waves ( $<0.5 \mathrm{~m}$, Carvalho et al., 2016). However, the $P$-wave section achieves a greater depth penetration and allows us to recognize multiple steep fault branches with a deep rooting without clear reverse or normal offset, suggesting predominant strike-slip kinematics, in agreement with fault outcrop studies and the regional stress field (e.g., Cabral et al., 2003).

\section{Reprocessing and Forward Modeling of S-Wave Reflection Data}

An elastic finite-difference code (Thorbecke and Draganov, 2011) was used to

To prevent spatial and temporal aliasing and optimize the acquisition parameters, walkaway noise tests were first carried out. A minimum source-receiver offset of $4 \mathrm{~m}$ was used and a spread of forty-eight $28 \mathrm{~Hz}$ receivers were spaced $1.5 \mathrm{~m}$ apart. Data were acquired with an inline end-on acquisition geometry, with a vertical (source) stack count of 4 . The source and receiver move up was equal to one receiver spacing, but to avoid interpretation problems caused by a varying fold along the stacked section, only 36 channels were used in the geometry file. This resulted in a constant common midpoint (CMP) stacked section with a fold of 18 .

The data processing was simple, to avoid deleting the subtle signature of shallow faulting in the data: geometry installation, vertical stacking, trace editing, first-arrival muting, gain correction, velocity analysis, spectral whitening (30-90 Hz), band-pass model the $S$-wave data at both VFX and CDR sites. Forward modeling was undertaken using the same acquisition parameters as in field experiments, whereas $S$-wave velocity was based on interval velocity calculated from the stacking velocities, adjusted through iterative modeling. For simplicity, fault branches were represented as rectangular low-velocity zones with 10\%-20\% less than the background layers, according to the velocity changes observed in the horizontal velocity analysis. For most fault branches, no vertical displacement was considered in the layer boundaries across the disturbed zone, that is, no vertical offset in the fault was considered. Initial results have been presented in Carvalho et al. (2016) in which further details on the modeling are explained.

The modeling of Carvalho et al. (2016) was revisited for the VFX site, and the model that produced the best match between 
(a)

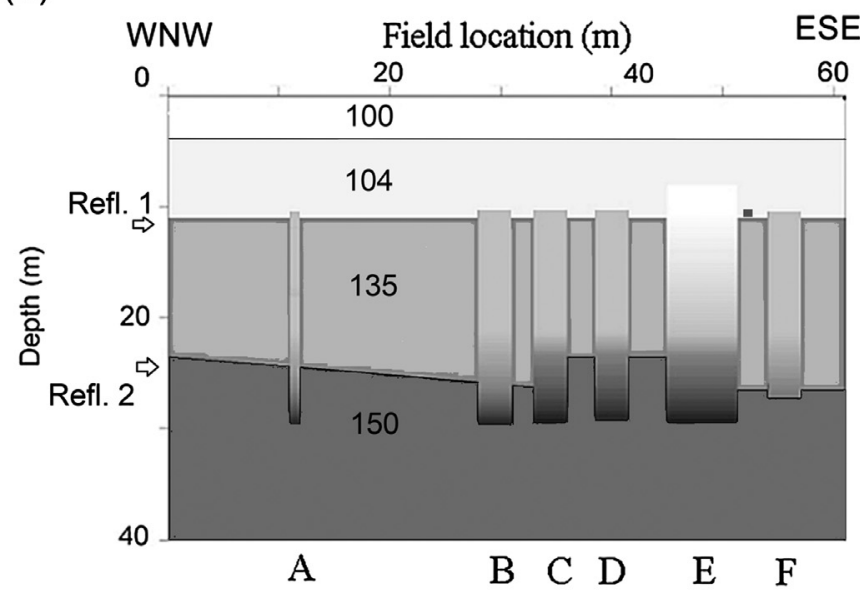

(b)

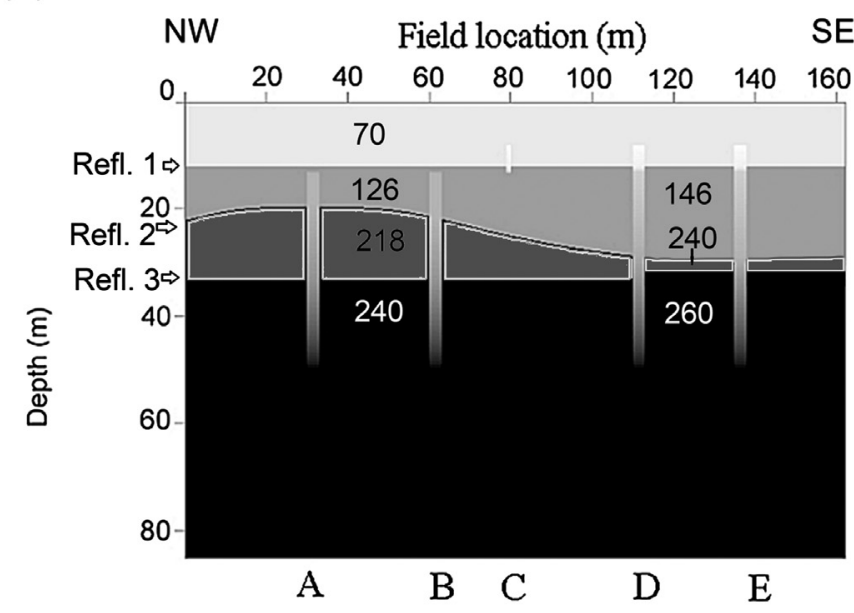

Figure 6. Velocity models used in the elastic modeling with fault branches represented as vertical, low-velocity zones (capital letters) for (a) VFX and (b) CDR sites. Numbers show S-wave velocities $(\mathrm{m} / \mathrm{s})$ used to match reflectors amplitude and arrival time. Location and width of the disturbed zones are assigned based on observed disturbances in S-wave reflection data, corroborated by $P$-wave, electrical resistivity tomography, and GPR data. Layer geometry based on seismic and borehole information. Refl 1 to Refl 3 indicate reflectors of the seismic sections.

synthetic and field data presents a sharp vertical offset of about $3 \mathrm{~m}$ at the top of the fourth layer of the model. Figure 6a displays this model. New CPT and borehole data presented here (see Fig. 3 and the New Borehole Data and Correlation with $S$-Wave Seismic Data section ) indicate that this seismic interface, placed at an average depth of about $28 \mathrm{~m}$, is probably an intra-alluvial sand-clay boundary and not the base of the alluvium, as assumed before this study.

Although there is no absolute age control for the lowermost unit of the alluvial sediments (coarse facies unit FU-1B of Vis and Kasse, 2009), it has been attributed to the Late Pleistocene (end of the last glacial maximum, at about 20-11 ky) based on its stratigraphic position. However, as stated earlier, the intra-alluvial sand-silt transition that has been detected in the seismic data possibly corresponds to the FU-4/FU-3A transition of Vis and Kasse (2009), which has been dated in the VFX core as about $10 \mathrm{ky}$ B.P. This has important implications for the evaluation of fault activity because the deformation detected at the fault has thus been accumulated in less time.

At CDR, previous modeling (Carvalho et al., 2016) assumed no vertical displacement across the fault branches (original processing did not show clear evidence of such displacement), but during data processing some doubts had arisen that reflector 2 (lense-shaped body) could pinch-out at about point $115 \mathrm{~m}$ with the occurrence of a jump at the top reflector 3 (top of layer 4 of Fig. 6b, fault D). It was therefore, decided to reprocess the data to check this hypothesis. The result is shown in Figure 4c. The reflectivity of the stacked section has clearly improved (see original processing of Carvalho et al., 2016), and a jump of reflector 3 (top of layer 4, Fig. 6) across fault $D$ is very plausible. As stated earlier, reflector 3 at CDR probably corresponds to the transition to the lowermost FU-1B unit of Vis and Kasse (2009), dated 14,120-13,809 cal. B.P. in a well sited about $2 \mathrm{~km}$ north of the CDR site (Freitas et al., unpublished report, 2018).

Therefore, the elastic modeling in this work was undertaken with varying vertical displacements for the top of layer 4 across fault $\mathrm{D}$, placed at point $115 \mathrm{~m}$ (Figs. $4 \mathrm{c}$ and $6 \mathrm{~b}$ ): 0, 3, 9, and $12 \mathrm{~m}$. These correspond to different thickness of the lens-shaped seismic body (unit 3) to the east of fault $\mathrm{D}$ of $9,6,3$, and $0 \mathrm{~m}$, respectively. Figure 7 shows several field shot gathers and correspondent synthetic gathers for vertical displacements of 0,3 , and $12 \mathrm{~m}$ across fault D. It can be seen that there is a better match between field and synthetic gathers for the vertical displacement of $3 \mathrm{~m}$. The arrival times of reflection hyperbolae for the shots east of fault D only match the arrival times of the field shot gathers for a modeled vertical offset of $3 \mathrm{~m}$ across the fault, while also considering a rise of velocity of $10-20 \mathrm{~m} / \mathrm{s}$ in the upper three layers to the east of fault $\mathrm{D}$ relative to the three layers velocity west of the fault. This velocity change across fault $\mathrm{D}$ is supported by velocity analysis (Carvalho et al., 2016). An alternative match of the arrival times can be obtained with a larger vertical offset across fault D. However, besides being geologically very improbable, these larger offsets do not reproduce as well other details observed in the shot gathers and the velocity field. The irregularities of reflector 3 observed in the field gathers, correspondent to perturbations in reflection hyperbolae (dashed arrows, Fig. 7), and the backscattered energy from the fault planes (black arrows, Fig. 7) are better reproduced in the synthetic gathers for the $3 \mathrm{~m}$ vertical offset.

\section{Discussion: Seismological Implications}

It is noteworthy to point out that the main characteristics of the field shot gathers and stacked sections can be reproduced in the synthetic gathers with relatively simple models based on borehole data, stacking velocities, and structural information of the field stacked sections. The fault branches in the models 
(a)

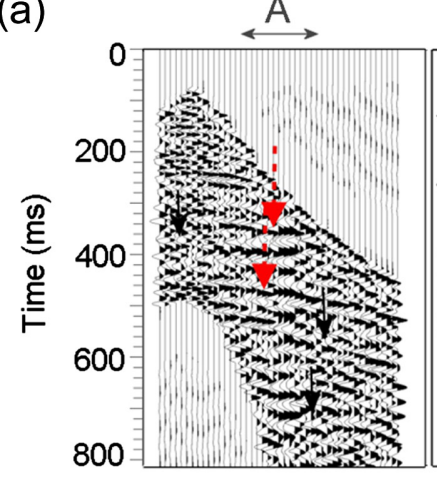

$\stackrel{B}{\longrightarrow}$

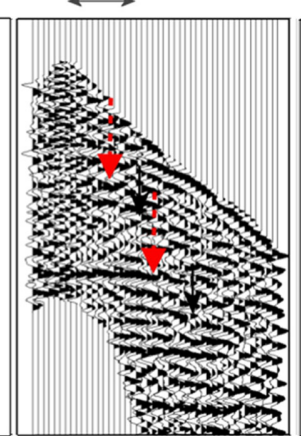

(b)

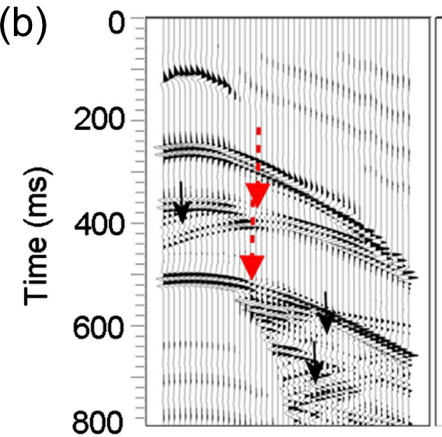

(c)

(c)

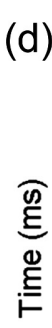

(d)
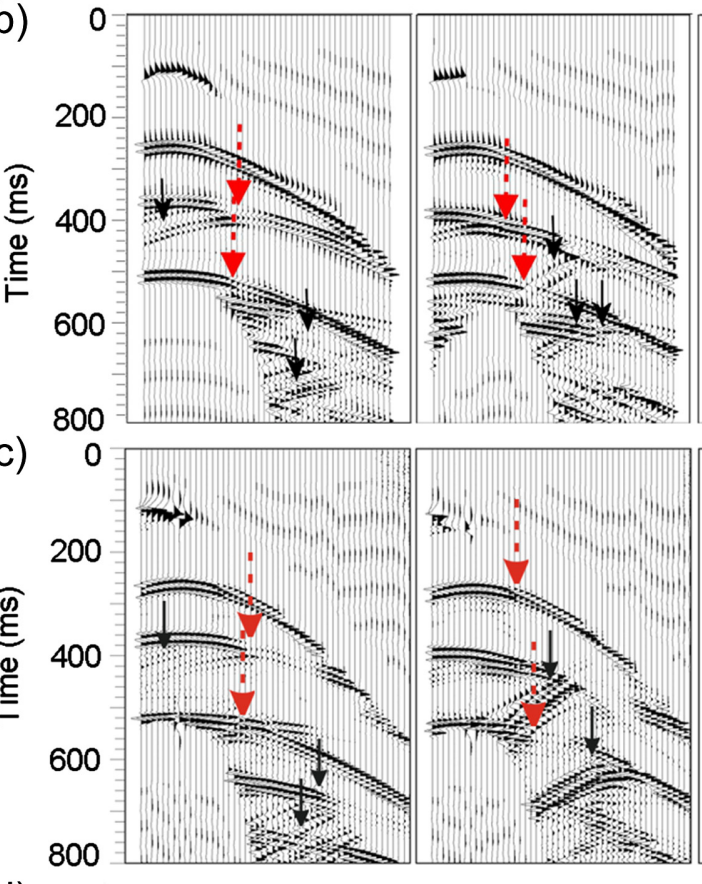
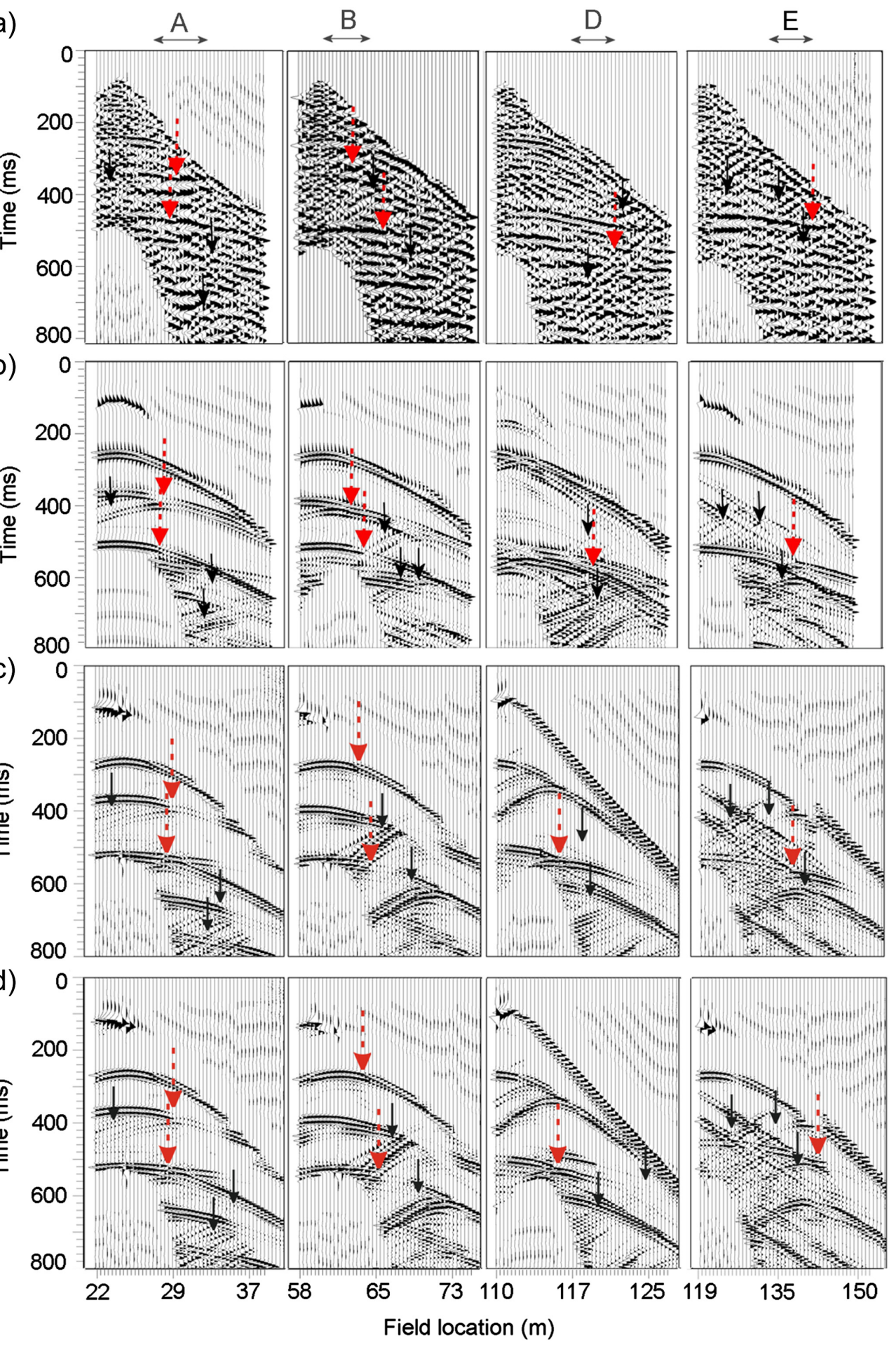

Figure 7. Field shot gathers (a) and synthetic gathers (b-d) for CDR site. (b) Results for a vertical offset of $0 \mathrm{~m}$ in layer 4 at fault D. (c) same for a vertical offset of $9 \mathrm{~m}$, as displayed in Figure 6 . (d) Identical for a vertical offset of $3 \mathrm{~m}$ and increase of velocity east of fault D by $10-20 \mathrm{~m} / \mathrm{s}$ in the three upper layers. (d) The best match between field and synthetic shots was obtained with a $3 \mathrm{~m}$ vertical offset and increase of velocity east of fault $D$. The top of this layer has been dated about $14 \mathrm{ky}$. The color version of this figure is available only in the electronic edition.

are simulated as narrow $(<2 \mathrm{~m})$, vertically emplaced low-velocity areas, often with no vertical discontinuity in the layer boundary across the fault. These faults have a constant velocity gradient with depth to maintain the velocity contrast with adjacent sediments, simulating a real-Earth situation in which the overburden stress increases with depth.

We have also modeled the data taking into consideration static and other geological effects, but several noteworthy features in the data can hardly be explained by geological (or anthropogenic) features other than faulting. This strongly suggests that the interpretation of soft-sediment faulting based on the seismic reflection data, also suggested by other geophysical data in places where local soil conditions allow, is generally valid. The $3 \mathrm{~m}$ vertical offset modeled at the top of layers 3 and 4 at the VFX and CDR sites, respectively, interpreted in this study as a stratigraphic surface dated B.P., must be considered an approximation as the true Earth is far more complex than admitted in our modeling.

Considering a 20-kilometer-long VFX fault that ruptures its entire length in maximum M 6.6-6.9 earthquakes, the expected average surface displacement per event should be in the $0.3-0.6 \mathrm{~m}$ range (Wells and Coppersmith, 1994; Stirling et al., 2002; Wesnousky, 2008). Assuming a pure dipslip kinematics for the fault and that the detected $3 \mathrm{~m}$ offset at the CDR profile is representative of cumulative average coseismic displacements, we can infer the occurrence of 
several surface rupture events in the last $14 \mathrm{ky}$. In the VFX profile, the detected deformation, also of $\sim 3 \mathrm{~m}$, affects an about 10-ky-old horizon, evidencing younger tectonic activity. If a fault length of $40 \mathrm{~km}$ is considered instead, as suggested by geological and geophysical data (Carvalho et al., 2008), and assuming that the fault ruptures along this length in maximum M 6.9-7.2 earthquakes, the expected average surface displacement per event should be larger, in the 0.4-1 m range (Wells and Coppersmith, 1994; Stirling et al., 2002) so that less events are needed to produce the detected deformation.

As mentioned in the Introduction section, the neotectonic setting of the VFX fault, which is acted on by a northwestsoutheast-oriented maximum compressive stress, strongly supports the idea that the fault has a significant strike-slip movement component. This leads to the inference that the offsets detected in the seismic profiles are only a fraction (the dip-slip component) of the true slip, thus increasing the fault-slip rate and reducing average earthquake recurrence.

As reflector 1 in the VFX seismic section (Fig. 3c), which we interpret as the transition of stratigraphic unit FU-5 to FU-4 of Vis and Kasse (2009), is apparently deformed, we conclude that the latest earthquake rupture occurred after the deposition of this horizon, approximately in the last $4 \mathrm{ky}$. As referred earlier, although we have trenched across the inferred trace of the VFX fault on the alluvial plain at the CDR site to search for any surface rupture on the fault during the 1531 LTV earthquake, the results were inconclusive due to the massive, plastic clays that were crossed, which lacked stratigraphic markers to detect offsets and probably have sealed any possible surficial ruptures. At the VFX site, the landowner did not allow the opening of a trench.

$S$-wave data indicate deformation in the first few meters and possible near-surface faulting, whereas GPR data show the presence of diffraction hyperbolae at 1-2 depth, coincident with the spatial location of possible faulting identified in the $S$-wave data. Although we cannot discard an anthropogenic origin for the ultra-shallow $(\sim 1-2 \mathrm{~m})$ geophysical anomalies at these locations, very shallow faulting is very probable, suggesting the occurrence of a recent earthquake, possibly the 1531 historical event, as suggested by other authors (Justo and Salwa, 1998; Baptista et al., 2014).

\section{Conclusions}

Geophysical evidence of coseismic deformation in shallow sediments has recently been interpreted at VFX and CDR sites in Portugal, mostly through the use of $S$-wave and $P$-wave reflection data. In this study, these findings are further corroborated by reprocessing and remodeling of the $S$-wave seismic data and in some places, where local soil conditions permitted, by other geophysical data, such as GPR and geoelectric data. We further used borehole and logging data to confirm that these sediments are of Quaternary age, and by dating the imaged seismic reflectors through stratigraphic correlations, we attempted to constrain the timing of the faulting. Trenches were opened at the
CDR site to verify the geophysical interpretation in the uppermost $5 \mathrm{~m}$ of the alluvium, but they did not provide any evidence of faulting due to the massif plastic-clayey sediments that were found, which lacked markers and probably sealed any fault rupture. Therefore, to constrain fault geometry and rupture offsets, we had to rely exclusively on the geophysical evidence, and for that purpose, we performed elastic forward modeling. A vertical offset of about $3 \mathrm{~m}$ (we have estimated vertical resolution of $\sim 0.5 \mathrm{~m}$ ) was detected at the VFX site, displacing a stratigraphic horizon dated approximately $10 \mathrm{ky}$, and a $10 \mathrm{~m}$ horizon dated around $4 \mathrm{ky}$ also shows clear signs of deformation. A similar offset of $3 \mathrm{~m}$ was detected at the CDR site, displacing a stratigraphic horizon dated approximately $14 \mathrm{ky}$, both sites evidencing fault activity in the Upper Pleistocene to Holocene. These ruptures are probably correlative of $\mathbf{M} \sim 7$ earthquakes, the last one occurring in 1531.

\section{Data and Resources}

All raw seismic reflection data (Society of Exploration Geophysicists [SEG]-2 or SEG-Y files) acquired in the framework of this work can be obtained on request by contacting the corresponding author. Digital geological data are owned by Laboratório Nacional de Energia e Geologia (www.lneg.pt) and are commercially available at http:// geoportal.lneg.pt//index.php?lg=en\&state=Inicio. Borehole reports are commercially available at http://geoportal.Ineg.pt/geoportal/ egeo/bds/tecnibase/ and can be obtained digitally (pdf) on request. All the websites were last accessed in April 2020. Supplemental material of this article includes electrical resistivity tomography, ground-penetrating radar data, and trench results, which were also acquired over the seismic line as they corroborated some of the seismic interpretations but did not supply new evidences.

\section{Acknowledgments}

The authors are grateful to the Portuguese Foundation for Science and Technology for financing projects ATESTA-PTDC/CTE-GIX/ 099548/2008, SISMOD/LISMOT-PTDC/CTE-GIN/82704/2006, and SFRH/BSAB/143063/2018, under which geophysical data were acquired. João Cabral is supported by Foundation for Science and Technology (FCT) project UIDB/50019/2020 - IDL (Instituto Dom Luíz). This work was also co-financed by the European Union through the European Regional Development Fund, included in the COMPETE 2020 through the ICT project (reference UID/GEO/ 04683/2019). The help in the fieldwork by Fernando Caneiras is highly appreciated. The authors are indebted to João Palha and João Lopes, the landowners of the Vila Franca de Xira (VFX) and Castanheira do Ribatejo (CDR) sites, respectively. The authors are also indebted to Editor-in-Chief Allison Bent, M. Malinowski, and an anonymous reviewer for their useful comments to improve this article.

\section{References}

Baptista, M. A., J. M. Miranda, and J. Batlló (2014). The 1531 Lisbon earthquake: A tsunami in the Tagus Estuary? Bull. Seismol. Soc. Am. 104, 2149-2161.

Benson, A. K., and N. B. Mustoe (1995). Analysing shallow faulting at a site in the Wasatch fault zone, Utah, USA, by integrating seismic, gravity, magnetic, and trench data, Eng. Geol. 40, 139-156. 
Cabral, J., C. Moniz, P. Ribeiro, P. Terrinha, and L. Matias (2003). Analysis of seismic reflection data as a toll for the seismotectonic assessment of a low activity intraplate basin-The Lower Tagus Valley (Portugal), J. Seismol. 7, 431-447.

Campbell, F. M., F. Ghisetti, A. E. Kaiser, A. G. Green, H. Horstmeyer, and A. R. Gorman (2010). Structure and evolution of the seismically active Ostler Fault Zone (New Zealand) based on interpretations of multiple high resolution seismic reflection profiles, Tectonophysics 495, 195-212.

Carvalho, J., J. Cabral, R. Gonçalves, L. Torres, and L. Mendes-Victor (2006). Geophysical methods applied to fault characterization and earthquake potential assessment in the Lower Tagus Valley, Portugal, Tectonophysics 418, 277-297.

Carvalho, J., R. Ghose, D. Alves, and J. Leote (2016). Earthquake faulting-related deformation in soil evidenced in $S$-wave shallow reflection data: Field results from Portugal, Geophysics 81, IM97-IM108.

Carvalho, J., T. Rabeh, J. Cabral, F. Carrilho, and J. M. Miranda (2008). Geophysical characterization of the Ota-Vila Franca de XiraLisbon-Sesimbra fault zone, Portugal, Geophys. J. Int. 174, 567-584.

Chapellier, D. (1992). Well Logging in Hydrogeology, A. A. Balkema Publishers, 175 pp.

Custódio, S., N. a. Dias, F. Carrilho, E. Góngora, I. Rio, C. Marreiros, I. Morais, P. Alves, and L. Matias (2015). Earthquakes in western Iberia: Improving the understanding of lithospheric deformation in a slowly deforming region, Geophys. J. Int. 203, 127-145.

Ferrão, C., M. Bezzeghoud, B. Caldeira, and J. F. Borges (2016). The seismicity of Portugal and its adjacent Atlantic region from 1300 to 2014: Maximum observed intensity (MOI) map, Seismol. Res. Lett. 87, 743-750.

Floyd, J. S., J. C. Mutter, A. M. Goodlife, and B. Taylor (2001). Evidence of fault weakness and fluid flow within an active lowangle normal fault, Nature 411, 779-783.

Ghose, R. (2012). A microelectromechanical system digital 3C array seismic cone penetrometer, Geophysics 77, WA99-WA107.

Ghose, R., and J. Goudswaard (2004). Integrating S-wave seismic reflection data and cone-penetration-test data using a multiangle multiscale approach, Geophysics 69, 440-459.

Ghose, R., J. Carvalho, and A. Loureiro (2013). Signature of fault zone deformation in near-surface soil visible in shear-wave seismic reflections, Geophys. Res. Lett. 40, 1074-1078.

Hale, D. (1984). Dip-moveout by Fourier transform, Geophysics 49, 741-757.

Justo, J. L., and C. Salwa (1998). The 1531 Lisbon earthquake, Bull. Seismol. Soc. Am. 88, 319-328.

Laboratório Nacional de Energia e Geologia (LNEG) (2010). Geological Map of Portugal. Scale 1: 1,000,000, Laboratório Nacional de Energia e Geologia, Alfragide, Portugal.
Ramalho, E. C., M. Marques da Silva, and A. Correia (2009). Diagrafias Aplicadas à Hidrogeologia, Palimage, 282 pp., ISBN: 978-972-8999-64-3 (in Portuguese).

Ramos, C., E. Reis, A. R. Pereira, T. M. Azevêdo, E. Nunes, M. C. Freitas, and C. Andrade (2002). Late Holocene evolution of the Lower Tagus alluvial plain and heavy metals content: Preliminary results, in Environmental Change and Water Sustainability, Study Group on Water Sustainability of the International Geographical Unit, J. M. Garcia-Ruiz, J. A. A. Jones, and J. Armaez (Editors), Zaragoza, 167-182.

Rasmussen, E. S., S. Lomholt, C. Anderson, and O. V. Vejbaek (1998). Aspects of the structural evolution of the Lusitanian Basin in Portugal and the shelf and slope area offshore Portugal, Tectonophysics 300, 199-225.

Stirling, M. W., D. A. Rhoades, and K. Berryman (2002). Comparison of earthquake scaling relations derived from data of the instrumental and preinstrumental era, Bull. Seismol. Soc. Am 92, 812-830.

Teves-Costa, P., J. Batlló, L. Matias, C. Catita, M. J. Jiménez, and M. García-Fernández (2019). Maximum intensity maps (MIM) for Portugal mainland, J. Seismol. 23, 417-440.

Thorbecke, J., and D. Draganov (2011). Finite-difference modeling experiments for seismic interferometry, Geophysics 76, H1-H18.

Vis, G., and C. Kasse (2009). Late Quaternary valley-fill succession of the Lower Tagus Valley, Portugal, Sediment. Geol. 221, 19-39.

Vis, G.-J., C. Kasse, D. Kroon, J. Vandenberghe, S. Jung, S. M. Lebreiro, and T. Rodrigues (2016). Time-integrated 3D approach of late Quaternary sediment-depocenter migration in the Tagus depositional systems: From river valley to abyssal plain, Earth Sci. Rev. 153, 192-211.

Wang, Z., I. P. Madlin, and E. W. Woolery (2004). Shallow SH-wave seismic investigation of the Mt. Angel fault, Northwest Oregon, USA, Tectonophysics 368, 105-117.

Wells, D. L., and K. J. Coppersmith (1994). New empirical relationships among magnitude, rupture length, rupture width, rupture area, and surface displacement, Bull. Seismol. Soc. Am. 84, 974-1002.

Wesnousky, S. G. (2008). Displacement and geometrical characteristics of earthquake surface ruptures: Issues and implications for seismic hazard analysis and the process of earthquake rupture, Bull. Seismol. Soc. Am. 98, 1609-1632.

Woolery, E. W., R. Street, Z. Wang, and J. B. Harris (1993). Near surface deformation in the New Madrid seismic zone as imaged by high-resolution $\mathrm{SH}$-wave seismic methods, Geophys. Res. Lett. 20, 1615-1618.

Manuscript received 17 October 2019 Published online 20 May 2020 